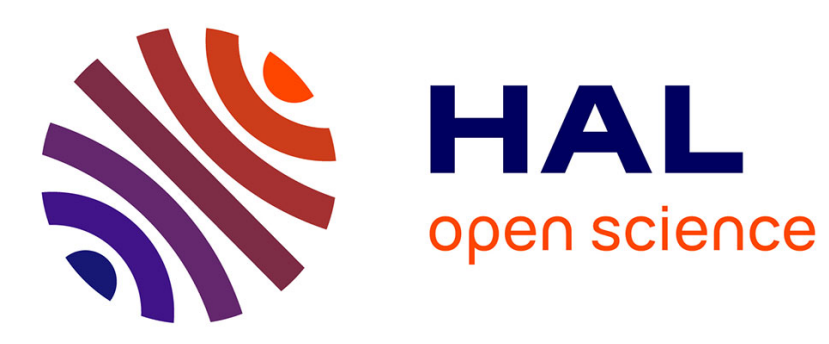

\title{
Grid technology reliability for flash flood forecasting: end-user assessment
}

Vincent Thiérion, Pierre-Alain Ayral, Jacob Geisel, Sophie Sauvagnargues, Olivier Payrastre

\section{- To cite this version:}

Vincent Thiérion, Pierre-Alain Ayral, Jacob Geisel, Sophie Sauvagnargues, Olivier Payrastre. Grid technology reliability for flash flood forecasting: end-user assessment. Journal of Grid Computing, 2011, 9 (3), pp.405-422. 10.1007/s10723-010-9173-9 . hal-00654052

HAL Id: hal-00654052

https://hal.science/hal-00654052

Submitted on 20 Dec 2011

HAL is a multi-disciplinary open access archive for the deposit and dissemination of scientific research documents, whether they are published or not. The documents may come from teaching and research institutions in France or abroad, or from public or private research centers.
L'archive ouverte pluridisciplinaire HAL, est destinée au dépôt et à la diffusion de documents scientifiques de niveau recherche, publiés ou non, émanant des établissements d'enseignement et de recherche français ou étrangers, des laboratoires publics ou privés. 


\title{
Grid technology reliability for flash flood forecasting: end-user assessment
}

\author{
Vincent Thierion . Pierre-Alain Ayral . Geisel Jacob. Sauvagnargues-Lesage Sophie . Payrastre Olivier
}

Thierion Vincent, Ayral Pierre-Alain, Geisel Jacob, Sauvagnargues-Lesage Sophie

Ecole des Mines d'Alès (LGEI) - 6, Avenue de Clavières - 30319 Alès Cedex

Tel.: 0033-466782791

E-mail: thierion.vincent@gmail.com, pierre-alain.ayral@ema.fr

Payrastre Olivier

Service de Prévision des Crues Grand Delta (SPC-GD) - 89 rue Weber - 30907 Nîmes Cedex

Tel.: 0033-466626200

\begin{abstract}
The flash flood forecasting is one of the most important challenges for research in hydrology. The anticipation of extreme hydrological scenarios through rainfall-runoff models is still limited, mainly because of the high uncertainty of rainfall forecasts and of limited computing resources. The authors propose to simulate an ensemble of potential hydrological scenarios in order to support the forecaster's decision-making process. The developed applicative layer takes advantage of the computing capabilities of grid technology, significantly enhancing the management of independent modelling operations in an operational lead time. A set of experimentations is deployed in order to firstly assess efficiency of this applicative layer and secondly to gauge more broadly the potentialities of grid to handle flood crisis management operations. Finally, in managing more than one hundred hydrological simulations simultaneously, this experimental platform opens new perspectives for the improvement of hydrological forecast modelling, limited until now by recurrent lack of computing resources.
\end{abstract}

\section{Keywords}

Flash flood, forecasting model, grid technology, gLite middleware, flood forecasting service, decision making

\section{Introduction}

Flash floods and more broadly flood phenomenon certainly represent with forests fires the most threatening natural hazard in Mediterranean region. Flash floods result from heavy precipitations on mountainous areas, e.g. $650 \mathrm{~mm}$ rain amount in $24 \mathrm{~h}$ in 2002 , caused by Mesoscale Convective Systems (MCS), generated on Mediterranean Sea [23]. Flash floods are characterized by specific time and space criteria [15, 29]. Generally, the short time of concentration (6-12 h) between the intense rainfall and the water rising (forecast lead time) and also 
the lack of reliable rainfall forecasts make early warning operations difficult [14, 38, 44]. Thus, two main efforts are required to cope with flash flood forecasting. On the one hand, researches are focussed on the understanding of hydrological processes implied in flash foods and hence on the improvement of models [3, 14]. On the other hand, present initiatives are also concentrated on developing powerful information systems integrating operational modelling capacities and the related real-time data streams [36]. This second issue is the motivation of this paper. Due to uncertainties especially in rainfall amount forecasts [44], one recommendation for the operational services is to take into account this intrinsic shortcoming, in producing multi-scenarios forecasting operations. The existing computing resources of operational flood services, such as the Grand Delta flood forecasting service (SPC-GD) are not enough for forecasting operations, even if they are increasing. This service confronted by extreme hydrological events and was considered as responsible for its difficulty to quantitatively anticipate those events, with spatial and temporal accuracy [28, 42].

In order to reach this operational objective, an access to extra computing resources appears mandatory. One suitable solution could be the access to compute resources available on Grid such as EGEE (Enabling Grids for EsciencE) during flash flood periods [21].

Over the last decade, computer technology considerably evolved from hardware and software point of view. In this context, the interconnection of geographically distant resources, the so-called grid technology, became workable and operational [46]. Unlike cluster computing, grid transcends institutional and geographical boundaries and brings together different heterogeneous networks, i.e. different bandwidths and latencies, within the same architecture [19, 34, 46]. Thus, grid is considered as a "hardware and software infrastructure that provides dependable, consistent, pervasive, and inexpensive access to high-end computational capabilities” [19]. In Europe, the grid project EGEE began to offer realistic perspectives for scientific communities [21] which increasingly instigated proof of concept initiatives in collaboration with computer scientists. The EGEE architecture provides an "infinite" pool of resources to end-users. High performance computing (HPC), such as supercomputing, cluster and grid, is generally dedicated to support important computational load, as required in this research. While clusters or supercomputers operate as a homogeneous system in gathering CPUs and storage devices located in the same physical location, a grid is per se highly disparate. Motivation of using large-scale grid infrastructure is precisely related to this high distribution of resources, in which no single point of failure (SPOF) exists. In this sense, grid technology provides continuous availability and a higher degree of reliability, in enabling a failover capability, a data replica process and an execution redundancy, in using a decentralized job management and scheduling system, as well as a redundant storage system. Since, information system's reliability appears as a critical requirement of crisis management operations [28], decision-makers and experts might use grid in order for their hydrological forecast modelling to execute with a higher degree of success. In this context, this paper focuses on the assessment of the grid technology and of an experimental platform for efficient flash flood forecasting operations. This issue has been one of the motivations for the establishment of the FP6 EC-founded project CYCLOPS [33]; more broadly oriented towards the bridge-building of Civil Protection and grid communities.

The main objective of this paper is to give feedbacks on the use of grid for handling intensive hydrological forecast modelling during flash flood situations. This paper is organised as follows. The Section 2 presents the Grand Delta flood forecasting service (SPC-GD) and its main processing requirements for the operational assignment. The motivations of this research are presented in Section 3. This Section overviews related works on 
the use of grid for environmental decision-making and elaborates the grid scheduling problem. Section 4 details the hydrological model used in this research and the technological characteristics of RRM-Grid (Rainfall Runoff Models on Grid) experimental platform developed for grid experimentations. In Section 5, the significant performances of this grid-enabled platform are provided and correlated to the concrete operational functioning of SPC-GD. Finally, the Section 6 is dedicated to conclude and to plan for future developments.

\section{SPC-GD information system and QoS requirements}

\subsection{Computing and data-processing functioning}

The SPC-GD manages a territory which is located in South East of France. Supervised rivers come from the Alps, for the ones situated in the eastern part of the zone, and from the Cevennes Massif, for the ones in the western part (Fig. 1). Two types of floods, e.g. plain and torrential, threat regularly this territory. The scope of this research is focused on thirty Cevennes watersheds and the forecasting of their respective discharge for flash flood events (eastern part).

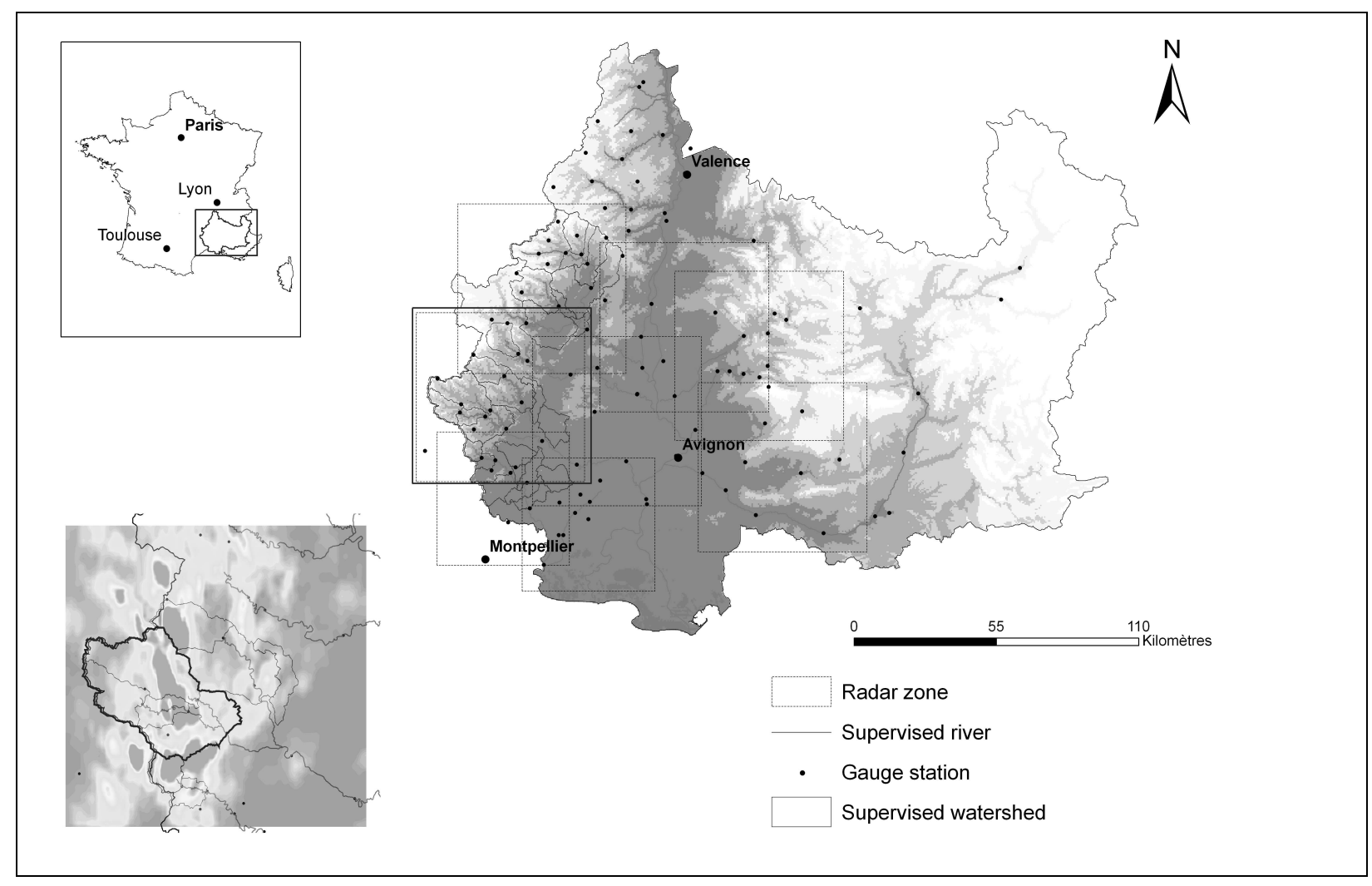

Fig. 1 SPC-GD competency territory

The SPC-GD's information system is based on the real-time monitoring of (Fig. 2):

- Ground-based radar system for the observation of rainfall provided by RHEA (Meteo-France).

- 174 stations composed by rain-gauges, and water-level recorders.

The computing architecture of SPC-GD's emergency room consists of a Local Area Network (LAN) composed of 3 application servers $(2 \times 1.5 \mathrm{GHz}), 1$ file server and half-dozen of client workstations. With a storage capacity lower than $1 \mathrm{~TB}(820 \mathrm{~GB})$ and approx. $1 \mathrm{~GB} / \mathrm{s}$ of bandwidth, this architecture handles the daily amount of 
computing of SPC-GD operations. The system is connected to an institutional virtual private network (VPN) with a throughput of $4 \mathrm{Mb} / \mathrm{s}$. These technological means allocated to the service are based on client-server architecture. The SPC-GD applications are provided by three different servers:

- The central server SIGMA2000 for managing imports/exports of ground sensors data, as well as the scheduling tasks of information system.

- CALAMAR calibrates the radar images with ground sensors data, provides utilities to manage them and exports images to private web site CALAMAR WEB.

- ALHTAÏR to simulate real-time watersheds' discharges (Section 4).

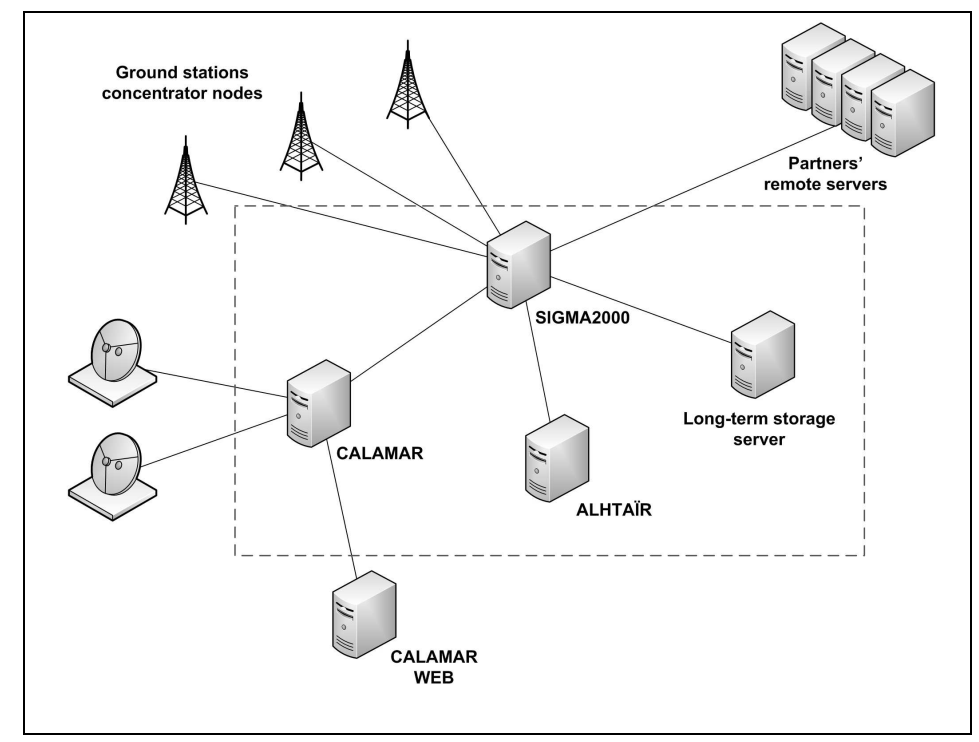

Fig 2 SPC-GD's information system

The collected data, enhanced by outputs of modelling tools, are analysed in real-time by forecasters. Their experience on hydrological functioning of Grand Delta territory enables them to deliver hydrological expertises to Civil Protection, institutional services and population

\subsection{Quality of Service (QoS) requirements}

Requirements for enhancements of the existing French flood management systems are based on the two last major flash floods in French Mediterranean area, the 12 and 13 November 1999 event in the Aude region [22] and the 8 and 9 September 2002 event in Gard region [15]. These inundations caused by upstream torrential flood (e.g. flash floods), generally occurring on fast-response basins, are less predictable in time and space than plain flood. In crisis situations, the forecast of flash floods requires to quickly anticipate the intensity of hydrological events by specifying the probable arrival time of flood crest and its discharge range [7, 11, 12].

The recommendations of experts to better anticipate flash flooding, i.e. provide an accurate level of hydrological vigilance, imply two main developments of forecasting capabilities, essential for efficient hydrological expertise:

- Robust and parsimonious multi-scale forecasting in order to manage hydrological heterogeneity of the Grand Delta territory, which signifies an increasing of the number of watersheds to simulate $[16,40]$.

- Multi-horizon and/or multi-source forecasts of meteorology in order to solve well-known uncertainty of small-scale meteorological forecasts [7, 40]. 
The result of the recommendations is a proposed experimental platform that should get in real-time different meteorological forecasts, and provide to forecasters a hydrological multi-scenario framework in order to refine temporally and spatially the description of the hydrological expertise. The accuracy of this expertise is fundamental for the success of the Civil Protection preparedness and response

The intrinsic functioning of Civil Protection, the particularities of flash floods management and the required increase of the computing load define specific QoS requirements for the development of such experimental platform. On the one hand, while real-time modelling of the runoff of watersheds is normally supported with the existing computing resources, these new forecasting operations require additional computational power ondemand to avoid an unexpected overload of the information system [32]. The SPC-GD's information system requires new resources purchasing in sending these forecasting operations to an external computing system such as a grid. In case of external resources the reliability of real-time monitoring could be kept, while on-demand hydrological forecasts could be intensively managed. On the other hand, the forecast lead time (i.e. duration expected to get simulation output) needs to be as short as possible [14]. This responsiveness is completely correlated to the required forecast horizon, i.e. time period at which the forecast is delivered, itself. For example, one-hour forecast is efficient if the output of the simulation is returned in less than half an hour. In the framework of this study, the requirement of computational time has been fixed to the half of the requested forecasting horizon, i.e. $30 \mathrm{~min}$ for a $1 \mathrm{~h}$ forecast, $1 \mathrm{~h}$ for a $2 \mathrm{~h}$ forecast, etc. in accordance with forecasters' recommendations.

Globally, crisis management operations require a real-time functioning of the platform while additional requirements have to be respected such as fault-tolerance capabilities and the continuous availability of grid resources [32]. For the former, potential malfunctioning has to be managed and reduced by specific reallocation utilities. The latter is more critical for two reasons, the first one is related to the difficulty to anticipate the amount of computing power required as it is directly related to the importance of the flash flood intensity and extension; The second one is related to the functioning of grid architecture like EGEE where there is neither high-priority jobs nor reservation of resources. Different solutions will be discussed in Section 5.

In order to propose a technological solution in respect with these requirements, the next section is dedicated to analyse related works on such end-users requirements as grid solutions for environmental management and frameworks supporting QoS requirements.

\section{Scientific motivations : related works}

\subsection{Grid for environmental decision-making issues}

The applications dedicated to environmental decision-making topics, as the one presented in this paper, require gathering geographically distant geospatial datasets and building modular workflows. Moreover, the geospatial datasets are mainly multi-dimensional, which requires complex and intensive-computing treatments. In operational context, stakeholders need to easily access data collected by remote equipments [37] and to develop "What-if" scenarios in order to assess intensity of coming hazards [35] 
This work is based on the results of researches on environmental problem-solving based on grid technology. As mentioned in [8, 18, 20, 25, 37], grid appears as an efficient technological solution to integrate factual data and dedicated tools among multiple stakeholders through an e-collaboration portal and throughout the expertise process. [30] and [37] exhibit the Sardinian grid infrastructure, GRIDA3, dedicated to enable the sharing of skills, tools and resources for multiple environmental topics, in particular hydrology. In the same manner, researches developed in the framework of MEDIGRID (http://www.eu-medin.org/) suggest the integration of fire propagation, hydrology, soil erosion and landslide models in a unique system based on grid architecture. These two projects have lead to developments of an experimental platform [12]. Some existing gaps can be bridged as shown by [35], who theorized the use of grid technology for designing of a powerful and flexible decision support system. Such system enables the rallying of research and operational teams in the scope of air quality decisionmaking.

Furthermore, hydrological and meteorological processes involved in flash floods events are manifold and interrelated. Thus, a complex and very modular workflow, which takes in account all the different input data and modelling operations, is the key parameter. The results of [20] demonstrate the usefulness of grid to support such requirements. Indeed, the Flood Crisis Grid project developed by the team of Community Grids Lab, worked on the real-time management of workflows adapted to users' requirements. The uncertainties of small-scale meteorological forecasts, also used in this research, imply, as suggested by [25], to develop a grid-enabled platform in charge of modelling different hydrological scenarios based on various determinist and probabilistic meteorological forecasts. Such scientific orientation is also suggested by [37] in order to (1) guarantee a minimal set of useful simulations in case of computing errors and (2) allow "parallel testing of alternative parameter settings". Finally, the use of grid technology to compute high number of independent simulations is also shared by [17]; the OpenSHA platform generates seismic hazard maps at approx. thousand sites. This last contribution clearly corresponds to the aforesaid requirements of this research.

Successes and experiences of these projects really motivated the improvement of flash flood forecasting from the technological point of view. The grid technology definitely shows its ability (1) to integrate resources (hardware, data, tools and skills), in a seamless way among multi-partners (2) to access on-demand computing and storage capacities in order to design a decision support system able to manage dynamic workflows and multi-scenario models and (3) to share results among geographically-distant teams. Compared to this set of researches, the originality of this approach lies in the hydrological uniqueness of flash floods and thus the short lead time of the forecasting operations. The present paper attempts to validate the effectiveness of grid to handle operational requirements of flash flood forecasting, in mainly focusing on a quantitative assessment of modelling capabilities characterized by short deadlines jobs (SDJ) [24].

\subsection{End-users reliability and QoS requirements in grid environment}

As shown in Section 2, the main requirement relative to flash flood forecasting operations concerns the responsiveness of the grid architecture. This issue is tackled by [24] which underlies the necessity to develop a scheduling layer on top of gLite middleware for eliminating the middleware overhead, providing a sustainable job output rate, and optimizing the failure recovery" which represent real limiting factors for SDJ management. These impediments are confirmed by the statistical analysis of [13] made on more than 2 millions of jobs submitted on EGEE grid middleware during 1 month, grid functioning being characterized by some significant metrics. 
Globally, one important metric concerns the medium percentage of malfunctioning jobs found higher than $30 \%$. Moreover, the durations of job registration, queuing and execution, represent the main contribution of the job turnaround time. Another major metric is related to the significant time duration for large-size input data transfer.

While the crisis management requires critical QoS requirements, e.g. short time of computation, a basic usage of gLite middleware seems not to be reliable enough. Given the volatility of grid resources [27, 41], three kinds of problems are generally identifiable on gLite and in grid in general:

- The grid-component outage often makes "failures" the rule rather than the exception in grid environments [27].

- Resources heterogeneity of grid may be the source of failures related to difference of version of libraries and software present on the site and needed by the application.

- Middleware overhead (queuing time) for short deadlines jobs increases the turnaround time [24].

In this context, [24] emphasises the importance of user-level scheduling to improve the quality of service for operational grid using. Through the research, the authors suggest using DIANE (Distributed Analysis Environment), an EGEE compliant framework. Many recent proposals also target the need of intelligent scheduling systems, such as meta-schedulers, on top of grid middleware. EMPEROR [1] is based on a time estimation algorithm which is attempted to minimize the running time of the job and DIANA [34] constantly evaluates a global indicator summarizing costs of job execution, data transfer and network characteristics so as to select the best resource to execute each job.

In order to reach QoS requirements of flash flood forecasting as well as to develop a high-end modelling platform, it appears crucial to take advantage of an automatic scheduling layer on top of gLite middleware able to control:

- Creation of jobs based on Job Description Language (JDL) developed with gLite middleware [9].

- Submission of jobs in minimizing the time for job allocation.

- Stand-alone control of jobs execution.

- Recovery operations of malfunctioning jobs.

- Retrieving the output of jobs as soon as algorithm execution is done.

Literature investigation guided the technical choices made in the development of this scheduling layer. If DIANA [34] and EMPEROR [1] meta-schedulers represent a real benefit for optimal allocation of jobs, these implementations are made at the middleware level whereas the presented research is related to an end-user level without administrator's privileges and is dependent on the provided software resources. On the other hand, two lightweight schedulers appeared good candidates for operational issues of this research: DIANE [24] and Pilot jobs [5]. They are based on dynamic pull approach which guarantees an efficient load-balancing. From the implementation point of view, both are generic and reusable for different topics. Choice has been made on Pilot jobs framework given the use of job collections, well-known to speed up the start-up phase, the lightweight RFIO protocol to access files on SE and its development in the scope of VO ESR activities.

Section 4 is dedicated to describe the components of the experimental platform (RRM-Grid) for supporting intensive hydrological computations in early warning operations. 


\section{Material and methods}

\subsection{SPC-GD modelling capacities : ALHTAÏR model}

\subsubsection{Description of the model}

The hydrological model used in this work is the distributed rainfall-runoff model ALHTAÏR [6]. The original inputs are data matrixes representing respectively rainfall intensity and watershed characteristics. For the former, it corresponds to ground-based radar system output, i.e. $64 \times 64 \mathrm{~km} 2$ zones with a $1 \mathrm{~km}$ resolution. For the latter, watersheds areas vary from one watershed to another from $60 \mathrm{~km} 2$ to $900 \mathrm{~km} 2$ with a resolution of $50 \mathrm{~m}$. These watersheds have quite short times of concentration and an average of slopes relatively steep (30 - 40\%). Watershed information is stored in irregular matrixes, whose size varies from 27000 to 470000 cells according to the watershed area.

This parsimonious model has an event-driven functioning, i.e. initial hydrological conditions are considered as null, and includes two different modules:

- The "production module" is dedicated to transform raw rainfall in effective rainfall. Geographical correspondences are on-the-fly calculated between rainfall and watershed matrixes. For each cell of the watershed, derived on the Horton principle [6, 26], this module calculates the local surface runoff according to the infiltration capacity. The general principle of this module is that the infiltration capacity is correlated to the rainfall intensity. New hydrological conditions are simulated and then used as input of the next time step.

- The "propagation module" which propagates the surface runoff of each watershed's cell to its outlet. The watershed data are derived to a digital elevation model (DEM) on which hydrological parameters (slopes and times of concentration) for each cell are calculated.

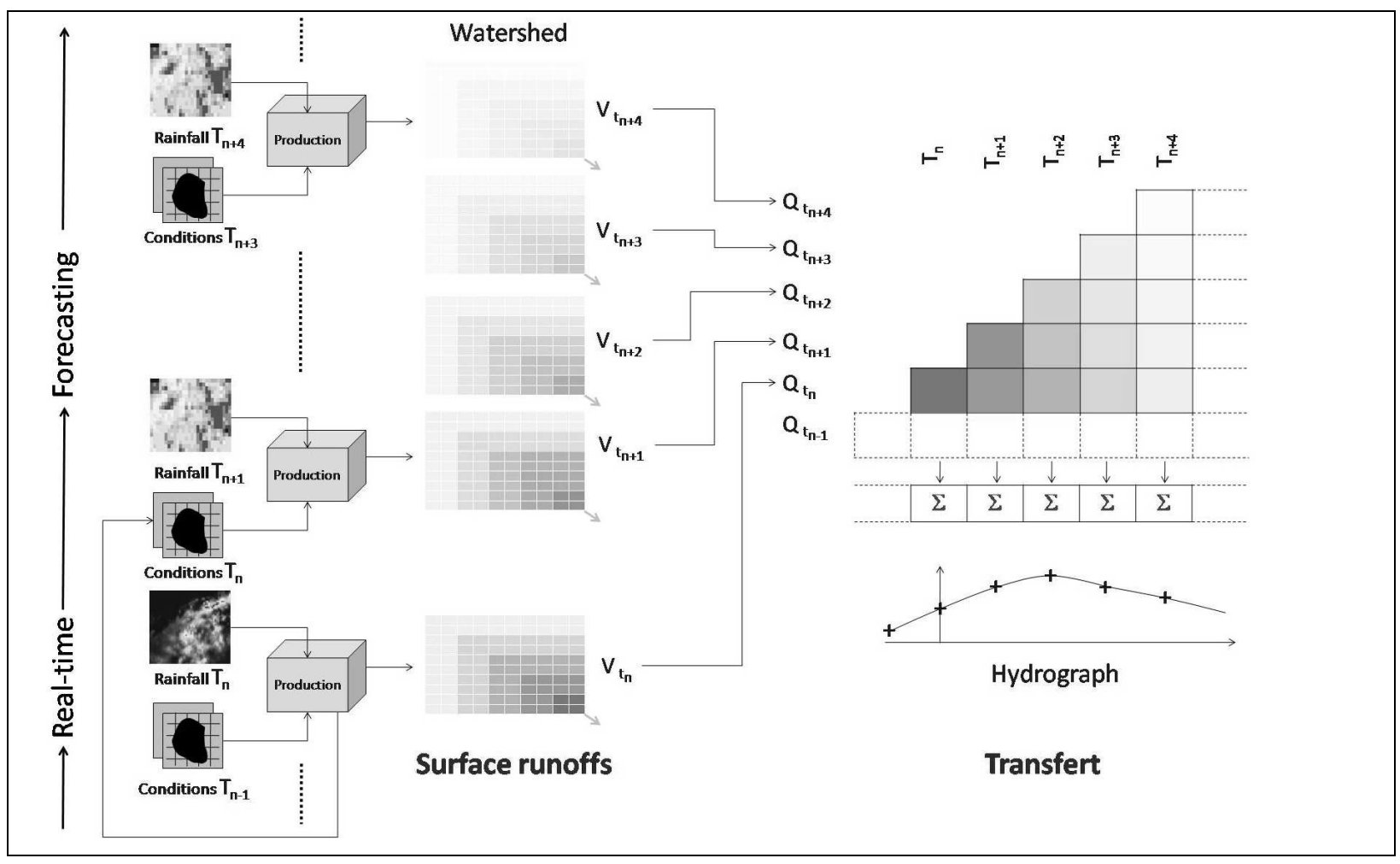


Fig. 3 ALHTAÏR model functioning

A complete run, i.e. production and propagation, generates respectively two different outputs, the new hydrological conditions of the watershed and the new hydrograph of the watershed's outlet (Fig. 3).

\subsubsection{Porting ALHTAÏR on the grid}

The first step is the porting of ALHTAÏR algorithms on EGEE architecture. The initial client-server ALTHAÏR application was based on a WINDEV@ environment. Thus, the initial objective was to extract and recode the core algorithms and adapt the input/output management to the grid constraints. Data have been recoded into the NetCDF (network Common Data Form) format, which enables efficient array-oriented scientific data management. The programming language used is Python given its modularity and lightness. In order to manage NetCDF files and matrix computation, two external python modules, Scientific Python and NumPy; have been compiled and used.

\subsection{RRM-GRID: an experimental framework}

Based on gLite middleware services, the experimental platform RRM-Grid uses two already tested frameworks, the RRM-Wrapper (data management) and the RRM-Parametric (job management). User can interact with these components through simple configuration file defining his own requests in term of simulations and data requirements.

\subsubsection{EGEE overview and gLite middleware technological basis}

The EGEE initiative provides to the researchers an access to the grid architecture, available 24 hours-a-day. This worldwide infrastructure connects more than 260 sites in about 50 countries and has a processing capacity higher than 330k jobs/day. The storage space, up to 50 petabytes, is shared among 200 virtual organizations representing more than 15 application domains [43]. The experimentations of this research have been made on the resources provided by the virtual organization (VO) Earth Science Research (ESR). The end-users have access to computing and storage resources, called computing element (CE) and storage element (SE), through a multi-services layer, called gLite middleware. The ongoing maturity of these top-level services results to the positive implementations made in the framework of current and past Grid projects, like DataGrid, DataTag, Globus, GriPhyN, iVDGL, EGEE and WLCG [9]. gLite services provide capabilities to handle the management of security, monitoring information, metadata, data and jobs by end-users and applications.

The certified users describe the job requirements via the Job Description Language (JDL) from his user interface (UI). Through JDL, users give details on the executable algorithm, on the list of input and output data to transfer (resp. called input sandbox and output sandbox) and on the computing requirements. The workload management system (WMS), in particular the workload manager (WM), interprets the job description, queries the information service (BDII) to identify compatible computing resources and puts the job in the chosen CE queue, before the local resource management system (LRMS) assigns it for execution on an available worker node (WN). Throughout the execution of the job, user can keeps informed on its status in requesting information to the logging and bookkeeping service (LB). 


\subsubsection{The RRM-Wrapper}

The RRM-Wrapper is based on the development made in the scope of the CYCLOPS project to manage data during the running process of grid jobs [45]. In order to limit time latency, this adapter design pattern launches the execution in controlling the management of inputs and outputs, and execution status.

The RRM-Wrapper prepares and places on the WN the last one-hour rainfall forecasting provided by RHEA, last hydrological conditions and last hydrograph. Once all the mandatory data are ready, the RRM-Wrapper launches production then transfer modules of ALHTAÏR. Once execution is finished, it uploads the output on SE predefined by the user.

\subsubsection{The RRM-Parametric}

The RRM-Parametric is based on the "Pilot jobs" framework developed by the team of II-SAS laboratory and presented by [5]. It is a lightweight, easy-to-use and open-source application dedicated to the grid jobs piloting. This framework has been originally designed for executing computational intensive astrophysical simulations.

On top of this application, the manager represents the supervisor of the application and automatically manages the treatment of a set of simulations requested by user. From UI, the manager communicates continuously with workers running on WNs, whose number, often proportional to simulations number, is defined by end-user. "Pilot jobs" uses the job collections framework provided by gLite to submit near-simultaneously all the workers. This WM's functionality speeds up the job submission time by reusing the same authentication for all the jobs in the collection [9]. The workers take in charge the simulations registered in a queue list on the UI, in following the common scheduling policy, FIFO (First In, First Out). Finally, this application is based on dynamic pull approach where each worker requests for a new simulation as soon as it finishes one. Once, all the simulations were executed, workers progressively set WNs free.

This generic framework can be adapted to many issues and is based on standard EGEE services. The manager runs in the background and automates the administrative tasks in order to minimize interactions between users and grid services. It automatically prepares the jobs, in generating JDL scripts, submits the predefined number of workers to the original EGEE WM and monitors them thanks to the LB service in order to keep informed end-users. The increase of performance is made possible with the use of job collections, with the limitation of jobs submitted, one worker manages several simulations successively, and with the fact that worker remains effective on WN throughout the simulations process.

To answer to the requirements of flash flood forecasting operations, the initial framework has been improved by adding three critical functionalities:

- Reallocation of malfunctioning jobs.

- Tasks priorities.

- Up-to-date whitelist and banlist.

In the perspective of a hydrological event, and before the effective launching of event-driven models, RRMparametric automatically submits a simple job, i.e. a dummy job with a simple shell command, to every CEs 
provided by the VO. The whitelist of CEs is filled with the ones whose jobs reached "done" status under 30 min. At the beginning of the modelling process, the manager prepares the queue list on a predefined workspace (RFIOenabled SE). RFIO (Remote File Input/Output) protocol enables a better management of files competitive access. Based on end-user request, it generates the configuration files (JSON language) used to generate JDL scripts in appending CEs elements of whitelist and banlist (GLUE attribute GlueCEUniqueID) and in sorting them by priority. In execution phase, a worker always treats the highest priority simulation first. Once the simulation finished, worker frees the allocated memory on the workspace and takes in charge the next simulation of the next highest priority (Fig. 4). For fault-tolerance management, simulations whose execution failed are reallocated into the queue list on the UI, while the banlist is automatically updated.

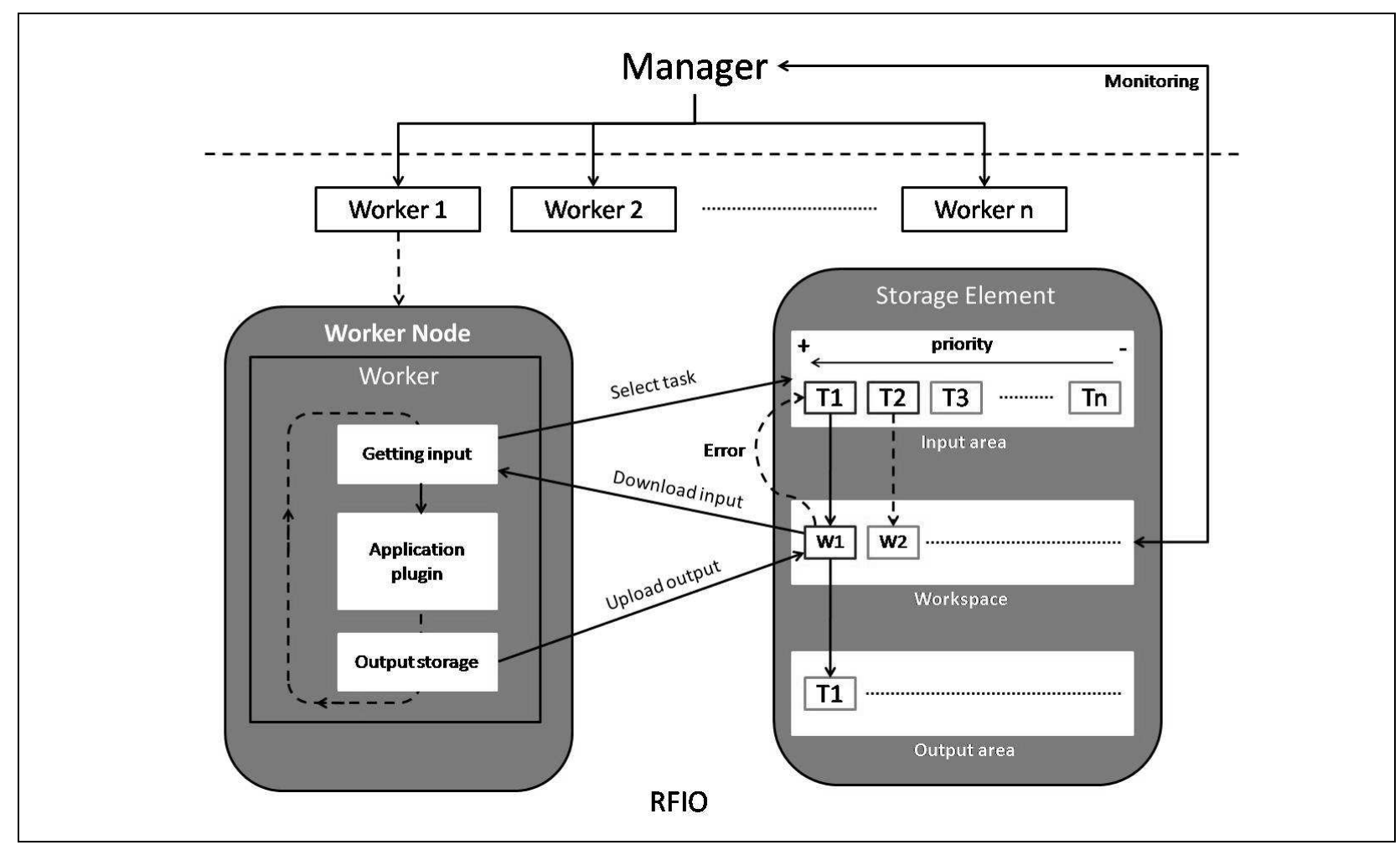

Fig. 4 RRM-Parametric adapted to flash flood requirements (adapted from [5])

\subsubsection{RRM-Grid: a lightweight job management platform for hydrological forecast modelling}

RRM-Grid is based on the encapsulation of RRM-Wrapper by RRM-Parametric. In order to launch the RRMGrid, the user fills a main configuration file (JSON language) which defines the parameters used to create the set of hydrological simulations (1). This configuration file contains:

- RFIO-enabled SE (workspace).

- SEs used to store input and output data.

- CEs used to submit the workers (whitelist and banlist).

- Local data to input in the model.

- Parameters of the core hydrological algorithms.

- Priorities of the simulations. 
The manager interprets this configuration file and automatically generates a configuration file for each simulation (2), upload these files on the workspace and the input files on predefined SEs (3), thanks to lcg_utils. The lcg_utils offers data management operations and logical files operations (interaction with grid file catalogue). From this point, the manager prepares workers (JDL) and submits them to the WMS (4 and 5). At the WN level, the RRMWrapper takes in charge the whole of the core algorithm preparation (6 and 7) and its execution (8) and finally places the output at the predefined SE (9).

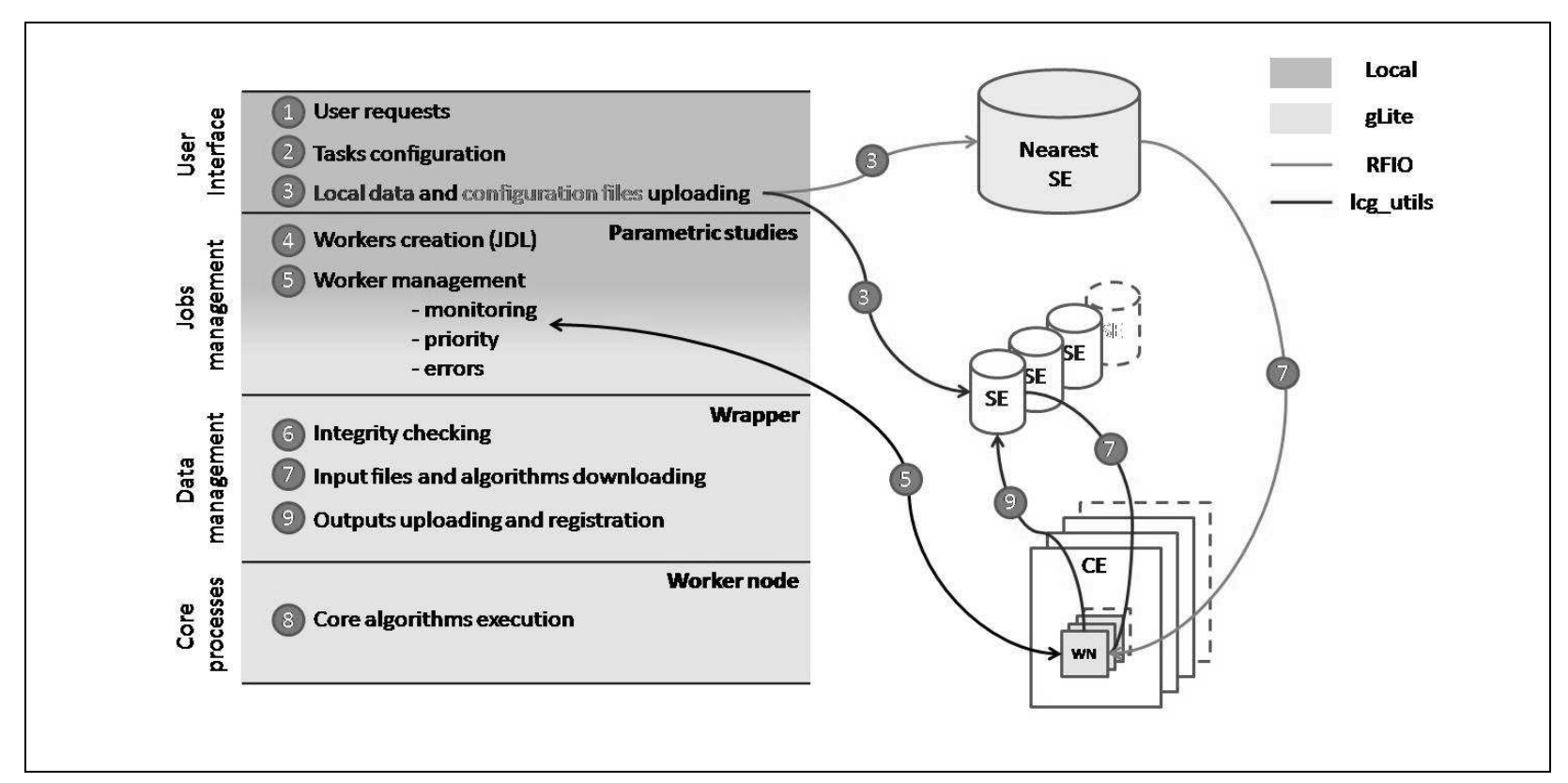

Fig. 5 RRM-Grid stand-alone workflow

On the local system, once a hydrological forecast is done, RRM-Grid downloads the corresponding hydrographs from SE and plugs it to the real-time one.

To demonstrate the effectiveness of this platform, a set of experimentations has been designed according to operational requirements.

\subsubsection{Experimental design definition}

The assessment of RRM-Grid is designed thanks to operational requirements defined with the SPC-GD actors (section 2). In order to demonstrate the capacity of RRM-Grid, the experimental design is based on three experimentations of jobs sequence simulating realistic hydrological scenarios forced by different meteorological situations. The forecast corresponds to the results of an ensemble of simulations with different values of the uncertainties on the original forecast of rainfall radar with a set of different forecasting horizon:

- 33 tasks simulating 1, 2 and 3 hours of forecast horizons with variations from $-50 \%$ to $50 \%$ with $10 \%$ step.

- 66 tasks simulating 1, 2 and 3 hours of forecast horizons with variations from $-50 \%$ to $50 \%$ with $5 \%$ step.

- 105 tasks simulating 1, 2, 3, 4 and 5 hours of forecast horizons with variations from $-50 \%$ to $50 \%$ with $5 \%$ step. 
Such a choice appears relatively representative of computational charge necessary for understanding the occurring hydrological event. A full intensive process of extreme simulation would imply several forecast horizons and rainfall variations for all of the watersheds. The choice of the three progressive sequences (from 33 to 105) can be explained by two main arguments. Firstly, it seems interesting to assess the effect of the number of jobs for the submission process. Secondly, in submitting 105 simulations, this experimentation is representative of complete operations of forecasting, in considering that the forecaster could request some simulations on most threatening rivers.

In the same philosophy of [13]'s methodology, the observed metrics concern the duration of main delay components that comprise the job processing in EGEE environment. The following analysis is based on 3 main time thresholds, i.e. the amount of time to reach a computing status (Tab. 1).

\begin{tabular}{|c|c|}
\hline Metric & Time threshold \\
\hline Submission & Duration to reach "Running" status \\
\hline Execution & Duration to reach the end of the ALHTAIIR algorithms running \\
\hline Validation & Duration to reach "Done" status \\
\hline
\end{tabular}

Tab. 1 Metrics observed in the experimental stage

Observations of turnaround durations have been also made on different forecast horizons. The results section attempts to attest the effectiveness of RRM-Grid performances in comparison with a basic grid usage.

\section{Results and discussions}

\subsection{Results of grid technology experimentation}

This section attempts to validate the efficiency of data management (RRM-Wrapper) and SDJ scheduling (RRMParametric) for flash flood forecasting.

The bottom, top and the middle line of the boxes on the Fig. 6 represent respectively the $25^{\text {th }}, 75^{\text {th }}$ and $75^{\text {th }}$ percentile of duration distribution for the three chosen metrics while the bottom and top lines are the minimum and maximum durations observed. The observation of these two box plots makes arisen various important indicators:

- The "Running" status is quicker reached with RRM-Wrapper, indeed 75\% of jobs begin to run in WN in less than $10 \mathrm{~min}$, while the same upper quartile corresponds to approx. $40 \mathrm{~min}$ with a basic grid usage.

- For "Validation" metric, a difference of $10 \mathrm{~min}$ is observed for the $75 \%$ percentile, in favour of RRM (just higher than $20 \mathrm{~min}$ against $30 \mathrm{~min}$ ).

- Even some differences exist for maximum values, they are important in both cases according to critical lead time required, e.g. some job allocations occurring after 2 hours for each usage.

- The duration of the model running is globally more stretched for RRM-Wrapper, 50\% of jobs have executed the model in more than $30 \mathrm{~min}$. 


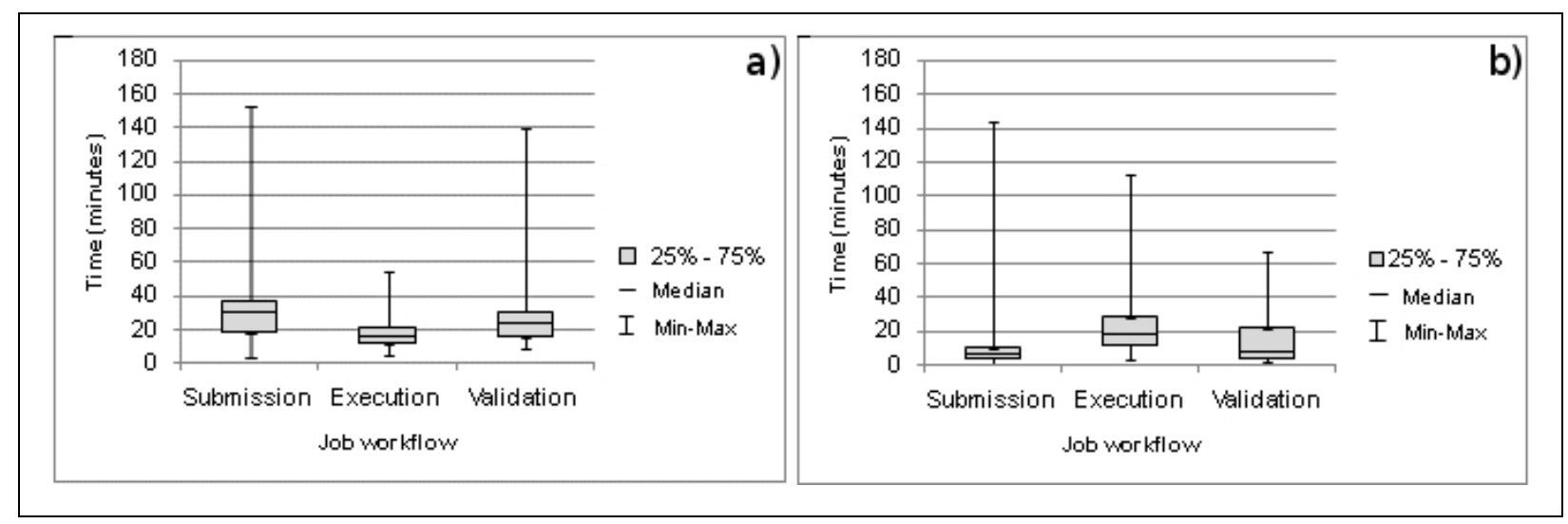

Fig. 6 Distribution of jobs stages duration (a: with basic grid usage, b: with RRM-Wrapper)

In analysing these observations, RRM-Wrapper speeds the beginning of the job on the WN, as well as the notification of the "done" status. This speedup is related to the input sandbox lightening, to the storage of outputs and the ultimate LB notification as soon as operation is done. However, with RRM-Wrapper the execution time trend is higher than without the RRM-Wrapper. The execution time increase is due to the management of input and output data management added to the core algorithm of the job. This limiting factor can be moderated given the higher bandwidth in the EGEE architecture and the general efficiency of turnaround duration. Finally, the significant values of maximum durations of RRM-Wrapper, as for basic grid usage, are mainly due to malfunctioning jobs which are not taken into account by RRM-Wrapper, while RRM-Parametric has this powerful capacity.

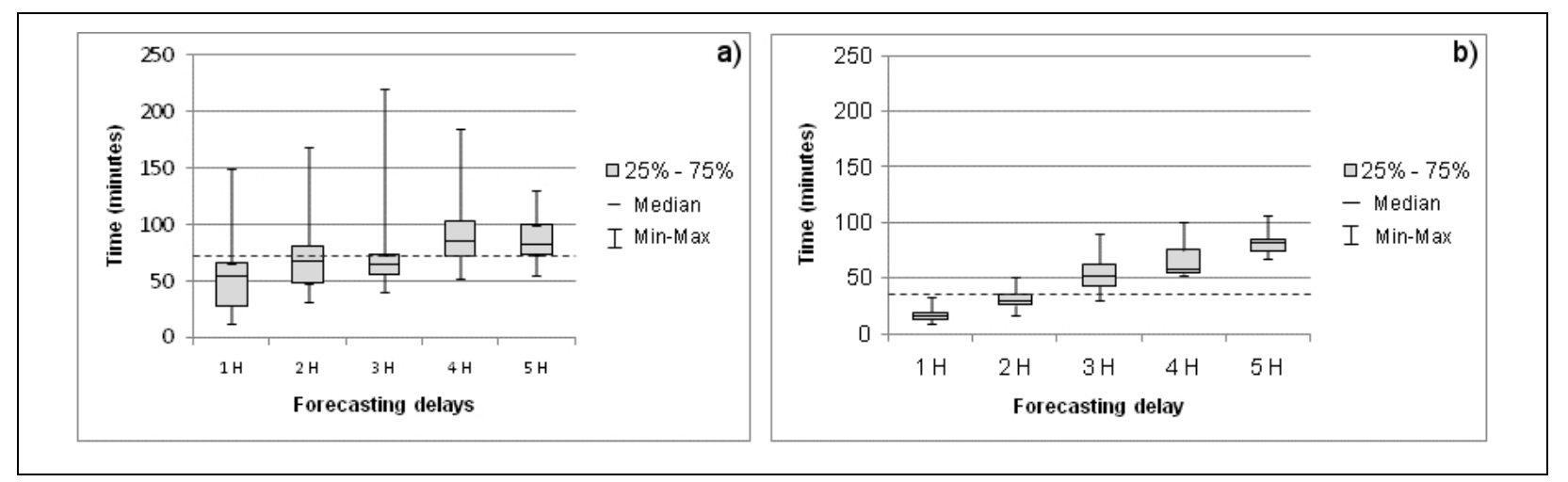

Fig. 7 Distribution of jobs durations by forecasting horizon (a: with basic grid usage, b: with RRM-Grid usage)

The box plots of Fig. 7 show the percentile of duration distribution according to forecast horizons. The main observations concerns:

- The shrunk shape of RRM-Grid plots (cf. Fig.7b). Indeed, its maximums and the box sizes are a lot lower than the ones of representing basic grid usage (cf. Fig.7a), confirmed by general medians (dashed lines). Moreover, in Fig.7b there is quite no overlap in time of the different boxes while it is not the case in basic grid case (Fig.7a).

- Most of the $1 \mathrm{~h}$ forecast simulations (more than 75\%) are treated and returned to the user in less than $30 \mathrm{~min}$, all the other forecast horizons are done on time. 
- The overall performance of both forecast operations, not completely interpretable from figures. With a basic grid usage, the average of success is around 60\% while with RRM-Grid, almost all the tasks (97\%) are treated successfully and on time.

Through these observations, the effectiveness of the malfunctioning-job reallocation functionality implemented in RRM-Parametric shows its efficiency. It also demonstrates the speed of the RRM-Parametric submission capacity, in addition to the one of RRM-Wrapper, enabled by the usage of standard job collections. Moreover, the clear separation among the different boxes confirms the availability of priority management and confirms the scheduling capacity of RRM-Grid (RRM-Wrapper + RRM-Parametric). It enables to launch in priority short forecasts horizons $(1 \mathrm{~h}$ and $2 \mathrm{~h}$ ), whose execution time is more critical. The small size of the boxes and the low maximum values point out that the set of jobs, for a given forecasting horizon, are treated almost simultaneously with relative stability.

The illustration of this effective improvement is shown in the last figure (Fig. 8). That represents detailed temporal information for each simulation instance. The diagonal line represents the time threshold beyond which simulations are considered as useless for operational purposes. It appears undeniable that RRM-GRID improves the workload management.

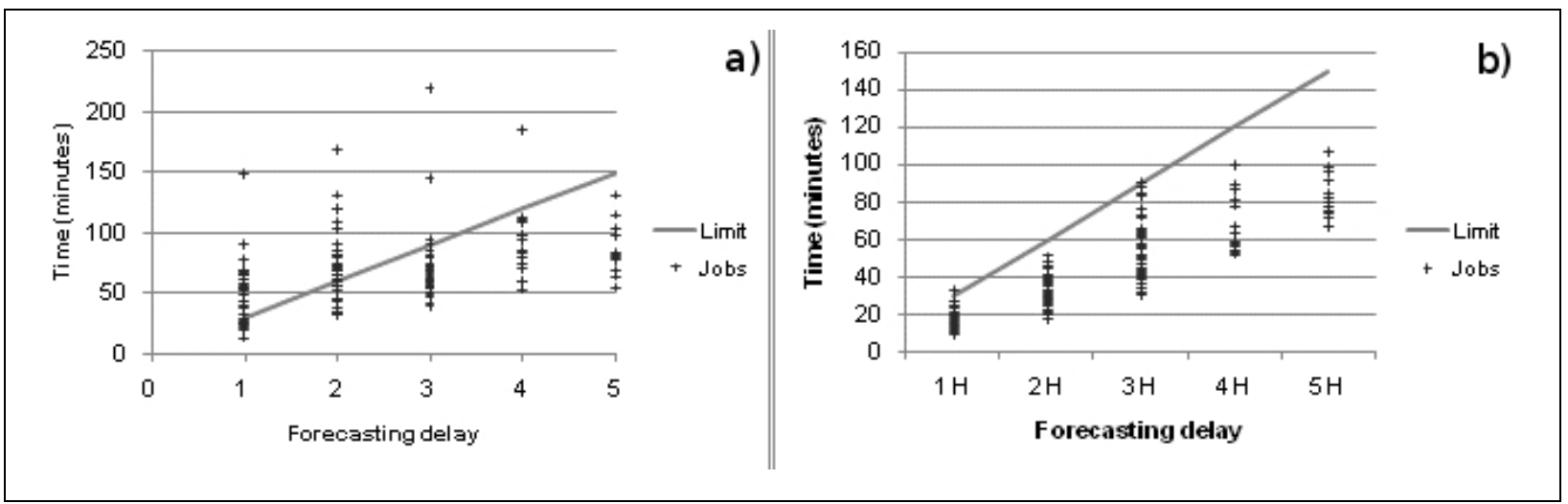

Fig. 8 Sample of treated jobs and operational time limit (a: with basic grid usage, b: with RRM-Grid using)

RRM-GRID, in giving full priority to short forecast horizons, manages the all set of simulations in an operational lead time in opposite to elementary jobs which suffer from an important heterogeneity of completion status and a lower number of successful jobs.

\subsection{Technological and operational interpretations}

This experimentation demonstrates the effectiveness of grid technology to solve intensive hydrological simulations handled by SDJ. With different levels of success, requirements detailed in Section 2 have been reached. This section summarizes the main outcomes of this research in linking them to next research issues in the long-term grid adoption process.

\subsubsection{High-end scheduling capabilties}

As explained hereinbefore, crisis management situations are characterized by temporal constraints. The faster and the more robust the expertise is developed, the better a decision can be made. The RRM-Grid implemented on 
Grid architecture corresponds to such situation in enabling near-real-time hydrological forecasts in remote computing resources. As shown in Section 4, operational lead times are generally respected. The most significant result concerns short forecasts horizons (1,2 and $3 \mathrm{~h}$ ), whose simulations have been generated in time for the quasi-totality. The priority management gives thus the forecaster the opportunity to control the scheduling in an easier way. The fault tolerance represents one of the most important impediments of gLite functioning while it appears as a crucial component of crisis management. As shown in the experimental section, RRM-GRID, by its capacity to reallocate malfunctioning jobs, improves grid reliability for this issue.

Further developments on the prediction of future resource (un)availability as presented by [41] could enhanced RRM-Grid fault-tolerance and scheduling efficiency. By implementing a multi-criteria predictor, the demonstrated method calculates statistically the potential availability of resources thanks to past and present monitoring data.

\subsubsection{On-demand computational power}

The VO ESR, in which experimentations have been made, provides for computing policy approx. 1200 job slots able to run simultaneously (https://cic.gridops.org/index.php?section=vo\&vo=esr). This computational power appears sufficient and gave on-the-fly new computing capacities to SPC-GD in the condition that there is no other intensive compute applications. Through RRM-Grid facilities, the SPC-GD forecaster has now the opportunity to quickly assess hydrometeorological multi-scenarios, without increasing too much the computational load of the existing SPC-GD's information system.

\section{Concluding remarks: grid adoption for flash flood forecasting}

The outcomes of RRM-GRID experimentations show EGEE infrastructure's effective ability, however this infrastructure does not support resources reservation policy. Hence, there is no guarantee on getting computation resources in case of grid overloading. The question is clearly in the scope of gLite current developments [39]. Among initiatives, [24] proposes the concept of Virtual Reservation (VRes) framework where the physical processors of a WN are virtualized (subset) into many virtual processors. These virtual processors can be preallocated to specific applications without block new submission operations on this WN and enable a full utilisation of the WN (or a site). Alternatively, [2] presents an OGSA (Open Grid Service Architecture) compliant tool, GQoSm able to handle resources reservation facilities in a grid environment. It focuses on the QoS negotiation leading up to resources reservation for real-time applications, e.g. a certain percentage of computational power. However, no guarantee is given on the turnaround time of execution.

In a more pragmatic view, different solutions could be foreseen in order to minimize a potential overload of grid resources and to guarantee reserved resources. On the one hand, the 22 French flood forecasting services and the National Flood Forecasting Service (SCHAPI) ultimately the Civil Protection services could harmonize and gather their resources for a dedicated grid infrastructure open or not to other VOs. Alternately, on the periphery of EGEE infrastructure, the LAN, in which SPC-GD's information system is included, connecting hundred of personal 
computers, could be use to form a Public Resource Computing (PRC) [4]. This solution is not really reliable given that the number of computers can fluctuate very much as a function of time.

\subsubsection{Pre-emption policies proposal}

In every instance, a well-adapted resources reservation policy has to be based on the 4 vigilance levels of the SPCGD expertise. These 4 institutional vigilance levels (green, yellow, orange and red) correspond to gradual hazard intensity and to recommendations of adapted behaviours of populations. [10] defines the concept of VO Breeding Environment (VBE) as a conceptual framework "that guarantees the preparedness of its members to quickly get engaged in collaboration processes". E-contracts could delineate the expected resources for handling crisis management operations according to each level of vigilance. In the crisis start-up period, resources providers, identified in the e-contract, progressively allocate resources to SPC-GD and SCHAPI usage, based on QoS requirements beforehand defined in the $\mathrm{VO}$ e-contract, and readapt their supply according to the hydrometeorological intensity.

\subsubsection{Scientific perspectives}

These scientific outcomes open new perspectives in the framework of this research:

(1) The increasing of computational resources gives the opportunity to tackle execution of more complex hydrological models and functionalities. The assimilation of river discharges to make parameters fitting real-time hydrological conditions appears as the most relevant candidate [7]. The computational power required for this process could be certainly tackled with data parallelization approach. The material used in the context of this research eases the development of such enhancements.

(2) The pervasive aspect of grid infrastructure argues for the development of a multi-institutional framework based on grid architecture to reach the interoperability requirement of crisis management [28]. The seminar of Crisis Management Initiative group held at Helsinki on 11-14 September 2003 defined the challenge of interoperability in crisis management as the connection of participants playing different roles at different locations with specific information requirements but following the same sequence of the crisis events. The design of grid architecture, as e-collaboration platform, in gathering heterogeneous resources in a "unified large-scale computational resource" [21], seems to make this interoperability issue possible $[8,18,30,33,37]$. In this sense, scientists and experts in hydrology could be gathered in a dedicated virtual organization. This community could share collected data and interact for hydrological processes understanding and expertise developments.

(3) Finally, the next issues in the field of operational hydrology should be directed towards the integration of flood risk management in guaranteeing the temporal continuity of data among partners from prevention to lessons learnt stages and in developing on-the-fly access of high-end toolboxes (Fig. 9). 


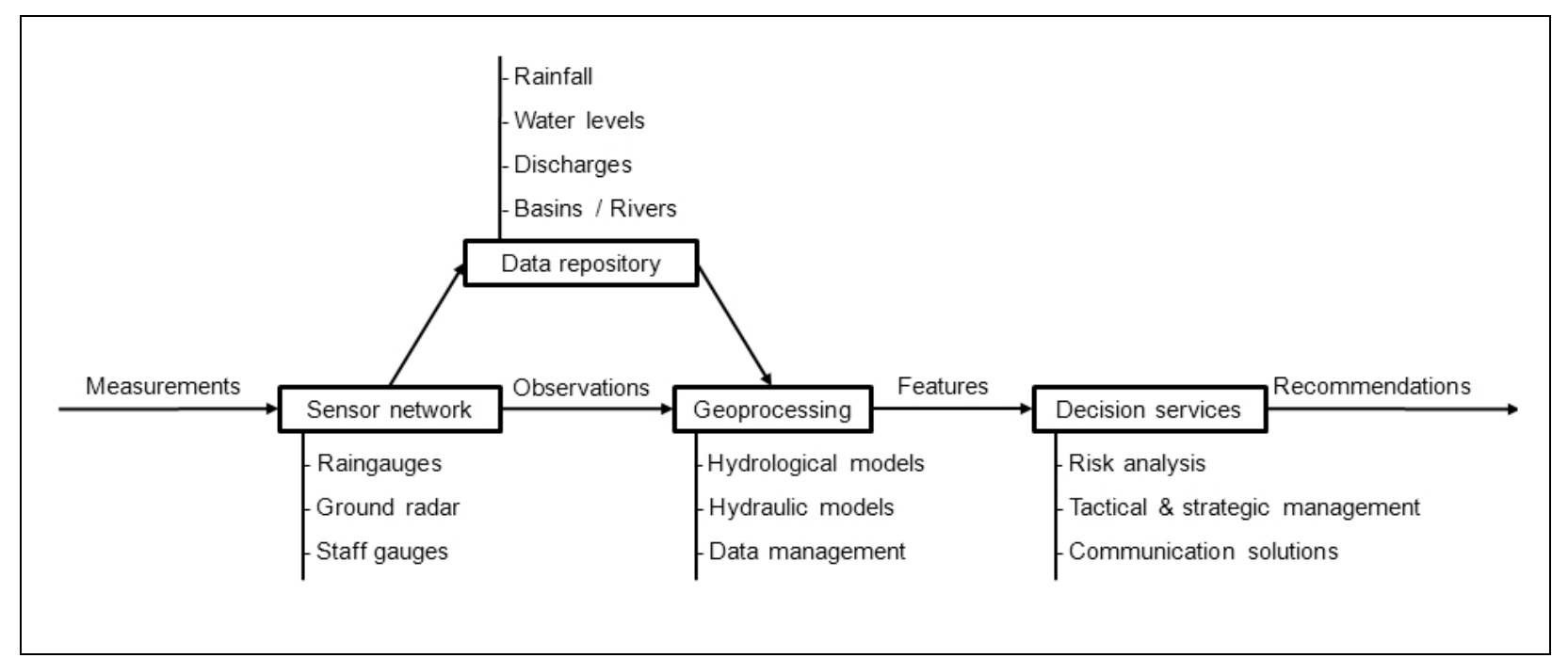

Fig. 9 Information system of flood management on grid (inspired by [31])

Bridging the gap between communities and gathering them in a unique information system involve the adoption of well-found standards. The collaboration between the communities of grid technology and Open Geospatial Consortium web services opens this opportunity [31].

The demonstrated availability of EGEE architecture has clearly given an effective and rapid response to forecasting of flash floods and shows positive arguments to operational decision-makers for further implications. However, a long-term experimentation has to be considered to implicate a real operational functioning. Indeed, the technological, operational and political obstacles are numerous in the process of effective adoption. New guaranties which are given by the ongoing evolutions of EGEE infrastructure, towards structured policy with local, national (NGI) and European initiatives (EGI), through the validation of a production state, enable to foresee a fully consideration of the operational partners.

\section{Acknowledgements}

This work makes use of results produced by the Enabling Grids for E-science E project, a project co-funded by the European Commission (Under contract number INFSO-RI-031688) through the Sixth Framework Programme. EGEE brings together 91 partners in 32 countries to provide a seamless Grid infrastructure available to the European research community $24 \mathrm{~h}$ a day. Full information is available at http://www.eu-egee.org.

This work has been developed with resources from Earth Science Research virtual organization of EGEE. The authors also wish to acknowledge the support of Dr. Monique Petitdidier (IPSL-LATMOS) for her support and fruitful discussions, and David Weissenbach (IPGP) for technical support of this research. The authors thank the forecasters of the SPC-GD for their contribution in the definition of the application.

\section{References}

1. Adzigogov, L., Soldatos, J., Polymenakos, L., EMPEROR: An OGSA Grid meta-scheduler based on dynamic resource predictions Journal of Grid computing, 3, 1, 19-37 (2005). 
2. Al-Ali, R.J., Amin, K., Von Laszewski, G., Rana, O.F., Walker, D.W., Hategan, M.,Zaluzec, N., Analysis and Provision of QoS for Distributed Grid Applications,Journal of Grid Computing, 2, 2, 163-182 (2004).

3. Ambroise, B., Streamflow generation within small rural catchments in a temperate environment: 2- Systemic and dynamic modelling, Revue des Sciences de l'Eau, 12, 123-153 (1999).

4. Anderson, D.P., BOINC: a system for public-resource computing and storage. In: Proc. of IEEE/ACM International Workshop on Grid Computing, Pittsburgh (2004).

5. Astalos, J., Huchly, L; Dobrucky, M. (2008) Experiences from porting the astrophysical simulation "the unified theory of Kuiper-belt and Oort-cloud formation" to EGEE Grid, 3rd user forum, Clermont Ferrand , France, 11-15 February 2008. Available via http://indico.cern.ch/contributionDisplay.py?contribId=139\&sessionId=19\&confId= 22351 .

6. Ayral, P.-A., Sauvagnargues-Lesage, S., Gay, S., Bressand, F., Forecasting Flash Floods with an Operational, Model Advances in natural and technological hazards research, Springer, 25, 335-352 (2007).

7. Beven, K., Rainfall-runoff modelling: the primer. Wiley, Chichester (2001).

8. Bovolo I., C., Abele, S., Bathurst, J., Caballero, D., Ciglan, M., Eftichidis, G., Simo, B., A distributed framework for multi-risk assessment of natural hazards used to model the effects of forest fire on hydrology and sediment yield, Computers and Geosciences, 35, 924-945 (2008).

9. Burke, S., Campana, S., Lanciotti, E., Méndez Lorenzo, P., Miccio, V., Nater, C., Santinelli, R., Sciabà, A. gLite 3 User Guide, Manuals Series, Worldwide LHC computing grid, (2009) Available via https://edms.cern.ch/file/722398/1.2/gLite-3-UserGuide.html.

10. Camarinha-Matos, L.M., Afsarmanesh, H., A framework for virtual organization creation in a breeding environment, Annual Reviews in Control 31, 119-135 (2007).

11. Chiang, Y.-M., Hsu K.-L., Chang F.J, Hong Y., Sorooshian S., Merging multiple precipitation sources for flash flood forecasting, Journal of Hydrology, 340, 183-196 (2007).

12. Claudet, R., Bouvier, C., Outils de prévision des crues rapides: les besoins de l'alerte et du suivi en temps réel, Colloque d'hydrotechnique, 176ème session du comité scientifique et technique, 15-16 Juin, Nîmes, France, 105112 (2004).

13. Christodoulopoulos, K., Gkamas, V., Varvarigos, E.A., Statistical Analysis and Modeling of Jobs in a Grid Environment, 6, 1, 77-101 (2008).

14. Collier, C. G., Flash flood forecasting: What are the limits of predictability ? Quarterly Journal of the Royal Meteorological Society, 133, 3-23 (2007)

15. Delrieu, G., Ducrocq, V., Gaume, E., Nicol, J., Payrastre, O., Yates, E., Kirstetter, P., Andrieu, H., Ayral, P.A., Bouvier, C., The catastrophic flash-flood event of 8--9 September 2002 in the Gard region, France: a first case study for the Cévennes--Vivarais Mediterranean Hydrometeorological Observatory Journal of Hydrometeorology, American Meteorological Society Boston, 6, 34-52 (2005).

16. Duband, D., Thinking over hydrometeorological forecasting, Houille Blanche, 1, 42-50 (2000).

17. Field, E. H., Gupta, V., Gupta, N., Maechling, P., Jordan, T. H., Hazard map calculations using grid computing, Seismological Research Letters, 76, 565-573 (2005).

18. Folino, G., Forestiero, A., Papuzzo, G., Spezzano, G., MOSE: A grid-enabled software platform to solve geoprocessing problems, Nuovo Cimento della Societa Italiana di Fisica sect. C, 28, 225-235 (2005).

19. Foster, I., Kesselman, C., The Grid 2: Blueprint for a New Computing Infrastructure. Morgan Kaufmann, San Francisco (2004). 
20. Gadgil, H., Choi, J., Engel, B., Fox, G., Ko, S., Pallickara, S., Pierce, M., Management of data streams for a real time flood simulation, Community Grids Lab Technical Report (2004).

21. Gagliardi, F., Jones, B., Grey, F., Begin, M., Heikkurinen, M., Building an infrastructure for scientific Grid computing: status and goals of the EGEE project, Philosophical Transactions of the Royal Society A: Mathematical, Physical and Engineering Sciences, The Royal Society, 363, 1729-1742 (2005).

22. Gaume, E., Livet, M., Desbordes, M., Villeneuve, J., Hydrological analysis of the river Aude, France, flash flood on 12 and 13 November 1999, Journal of Hydrology, 286, 135-154 (2004).

23. Gaume, E., V. Bain, Bernadara, P., Newinger, O., Barbuc, M., Bateman, A., Blaskovicova, L., Blösh, G., Borg, M., Dumitrescu, A., Daliakopoulos, I., Garcia, J., Imirescu, A., Kohnova, S., Koutroulis, A., Marchi, L., Matreata, S., Medina, V., Preciso, E., Sempere-Torres, D., Stancalie, G., Szolgay, J., Tsanis, I., Velasco, D., Viglione, A., A compilation of data on European flash floods. Journal of Hydrology, 367, 70-78 (2009).

24. Germain-Renaud, C., Loomis, C., Mościcki, J.T., Texier, R., Scheduling for Responsive Grids, 6, 1, 15-27 (2008).

25. Hluchy, L., Astalos, J., Dobrucky, M., Habala, O., Simo, B., Tran, V. D., Flood forecasting in a grid computing environment, Parallel Processing and Applied Mathematics, 3019, 831-839 (2003).

26. Horton R.E., The role of infiltration in the hydrological cycle, Trans. Am. Geophys. Union, 14, 446-460 (1933).

27. Huedo, E., Montero, R., Llorente, I. M., Evaluating the reliability of computational grids from the end user's point of view, journal of Systems architecture, 52, 727-736 (2006).

28. Huet, P., Martin, X., Prime, J. L., Foin, P., Laurain, C., Cannard, P., Retour d'expérience des crues de septembre 2002 dans les départements du Gard, de l'Hérault, du Vaucluse, des Bouches-du-Rhône, de l'Ardèche et de la Drôme, Inspection Générale de l'Environnement, Paris (2003).

29. Kobiyama, M., Goerl, R., Quantitative method to distinguish flood and flash flood as disasters, SUISUI Hydrological Research Letters, 1, 11-14 (2007).

30. Lecca, G., Lai, C., Murgia, F., Biddau, R., Fanfani, L., Maggi, P., AQUAGRID: an extensible platform for collaborative problem solving in groundwater protection, Earth Science Informatics, 2, 83-95 (2009).

31. Lee, C., Percivall, G., Standards-based computing capabilities for distributed geospatial applications, Computer, 41, 50-57 (2008).

32. Mazzetti, P., Nativi, S., Esteves, A., Sá, V., Lebreiro, N., Thierion, V., Verlato, M., Research Strategies for the development of a Civil, Report on CYCLOPS (CYber-Infrastructure for CiviL protection Operative ProcedureS) Project. CYCLOPS-WP04-D16-IMAA. (2008) Available via http://www.cyclopsproject.eu/Default.aspx ? id_menu=9\&id_documento=47\&id_versione=1.

33. Mazzetti, P., Nativi, S., Angelini, V., Verlato, M., Fiorucci, P., A grid platform for the European Civil Protection e-infrastruture: the forest fires use scenario, Earth Science Informatics, 2, 53-62 (2009).

34. McClatchey, R., Anjum, A., Stockinger, H., Ali, A., Willers, I., Thomas, M., Data intensive and network aware (DIANA) grid scheduling, Journal of Grid computing, 5, 1, 43-64 (2007).

35. Mineter, M., Dowers, S., Skouloudis, A., Jarvis, C., Towards use of grids in environmental research, management and policy, International Journal of Environment and Pollution, 20, 297-308 (2003).

36. Montz, B., Gruntfest, E., Flash flood mitigation: recommendations for research and applications, Global Environmental Change B: Environmental Hazards, 4, 15-22 (2002). 
37. Murgia, F., Biddau, R., Concas, A., Demontis, R., Fanfani, L., Heilmann, Z., Lai, C., Lecca, G., Lorrai, E., Marrocu, M., GRIDA3: a shared resources manager for environmental data analysis and applications, Earth Science Informatics, 2, 5-21 (2009).

38. Norbiato, D., Borga M., Esposti S.D., Gaume, E., Anquetin S., Flash flood warning based on rainfall thresholds and soil moisture conditions: An assessment for gauged and ungauged basins, Journal of Hydrology, 362, 274-290 (2008).

39. Pacini, F., Maraschini, A. Job description language attributes specification - for the gLite middleware (submission through WMProxy service), EGEE Tech. Rep., 590869 (2007) Available via https://edms.cern.ch/file/590869/1/EGEE-JRA1-TEC-590869-JDL-Attributes-v0-9.pdf.

40. Rabuffetti, D., Barbero, S., Operational hydro-meteorogical warning and real-time flood forecasting: the Piemonte region case study, Hydrology and Earth Systems Sciences, 9, 457-466 (2005).

41. Rood, B., Lewis, M. J., Grid Resource Availability Prediction-Based Scheduling and Task Replication, 7, 4, 479-500 (2009).

42. Sauvagnargues-Lesage, S., Thierion, V., Ayral, P.-A., Mazzeti, P., Mangione, D. and Nardin, P. Use-cases Analysis Document, Report on CYCLOPS (CYber-Infrastructure for CiviL protection Operative ProcedureS) Project. CYCLOPSWP03-D9-DDSC. (2007) Available via http://www.cyclops-project.eu/Default.aspx?id_menu $=9 \&$ id_documento=32\&id_versione $=1$.

43. The EGEE project homepage: http://project.eu-egee.org.

44. Toukourou, M., Johannet, A., Dreyfus, G., Ayral, P.-A., Rainfall-runoff modelling for flash floods: the case of "Cévenol flash floods", Journal of Applied Intelligence (in press).

45. Verlato, M., Dal Pra, S., Angelini, V., D’Andrea, M., Frizziero, E., Squizzato, S., Pina, A., Esteves, A., Sa, V., Marques, R., Thierion, V., Ayral, P.-A., Dissemination and coordination activity, Report on CYCLOPS (CYberInfrastructure for CiviL protection Operative ProcedureS) Project. CYCLOPS-WP02-D17-INFN-002. (2008) Available via http://www.cyclops-project.eu/Default.aspx?id_menu=9\&id_documento=55\&id_versione=1.

46. Von Laszewski,, G., Wagstrom, P., Tools and environments for parallel and distributed computing, in Series on parallel and distributed computing, Wiley, Chapter Gestalt of the grid, pp. 149-187 (2004). 